Asian Spine Journal

Vol. 3, No. 1, pp 27 31, 2009

\title{
20-Year-Follow up of Treatment Using Spine Osteotomy and Halo-pelvic Traction for Tuberculous Kyphosis - A Case Report -
}

\author{
Nam-Hyun Kim, Ho-Joong Kim, Seong-Hwan Moon, Hwan-Mo Lee \\ Department of Orthopedic Surgery, Yonsei University College of Medicine, Seoul, Korea
}

\begin{abstract}
A 23-year-old male whose medical history included tuberculous spondylitis presented with a kyphotic deformity and incomplete paraplegia of twenty days duration. Preoperative radiographs demonstrated a T12-L4 kyphotic Cobb's angle of $100^{\circ}$ with a complete block showing on the lumbar myelogram at L4-5. The patient underwent anterior osteotomy and release. After the operation, a halo-pelvic apparatus was fit onto the patient, and distraction was begun. After distraction for 2 months, posterior osteotomy and release was performed for final correction, and distraction was maintained for anoth er three weeks. Finally, the kyphotic deformity was corrected to a Cobb's angle of $62^{\circ}$ from T12 to L4. Supplementary anterior fusion was done, and the apparatus was removed after consolidation of the fusion mass.

Even twenty years after correction of a tuberculous kyphosis, he had no neurological deterioration, and could work as a farmer using agricultural machines. Correction angle and sagittal balance were well maintained.
\end{abstract}

Key Words: Tuberculous kyphosis, Halo-pelvic traction, Spine osteotomy

\section{Introduction}

Since halo-pelvic traction was first demonstrated in 1971 by O'Brien et al.', excellent clinical results have been reported for the treatment of spine deformities such as kyphosis and scoliosis even though more recently these procedure have not been popular ${ }^{1,2}$.

In this report, we describe a clinical case in which the authors had treated a patient with tuberculous kyphosis about 30 years ago and had followed this patient for 20 years after the correction. We now report 20-year-follow-up results of the osteotomy and halo-pelvic traction treatment for tuberculous kyphosis.

\section{Case Report}

In 1976, a 23-year-old male with tuberculous kyphosis presented with incomplete bilateral paraplegia of his legs of twenty days duration. He was not able to stand or walk without any assistance due to motor weakness and sensory disturbances in both lower extremities. He had disabling back pain, and muscle weakness of his lower extremities had gradually been getting worse (Fig. 1).

He remembered that his kyphotic deformity started about 20 years ago. The patient's past medical history included tuberculous meningitis seven years ago. He took anti-tuberculous medications. A fistula was formed in the posterior lower back area six years ago, but it healed spontaneously. On admission, preoperative radiographs demonstrated a

Received Mar 30, 2009; 1st revised Apr 30, 2009; accepted May 1, 2009

Corresponding author: Hwan-Mo Lee, MD

Department of Orthopedic Surgery, Yonsei University College of Medicine

134 Shinchondong, Seodaemunku, Seoul, Korea

Tel: +82-2-2228-2191 Fax: +82-2-363-1139, E-mail: hwanlee@yuhs.ac

Copyright (C) 2009 by Korean Society of Spine Surgery

This is an Open Access article distributed under the terms of the Creative Commons Attribution Non-Commercial License (http://creativecommons.org/licenses/by-nc/3.0)

which permits unrestricted non-commercial use, distribution, and reproduction in any medium, provided the original work is properly cited.
Asian Spine Journal 


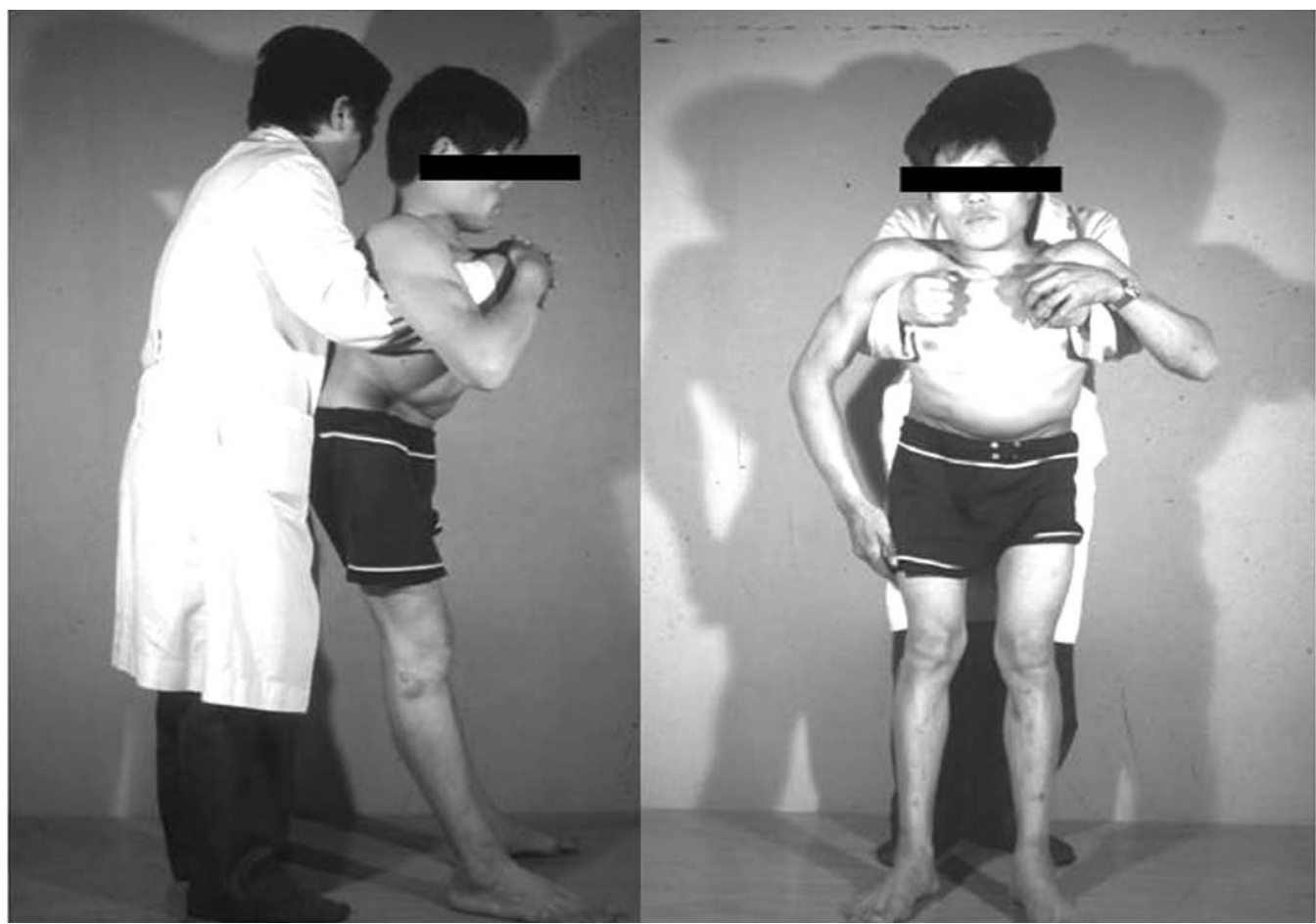

Fig. 1. The patient could not stand without any assistance.

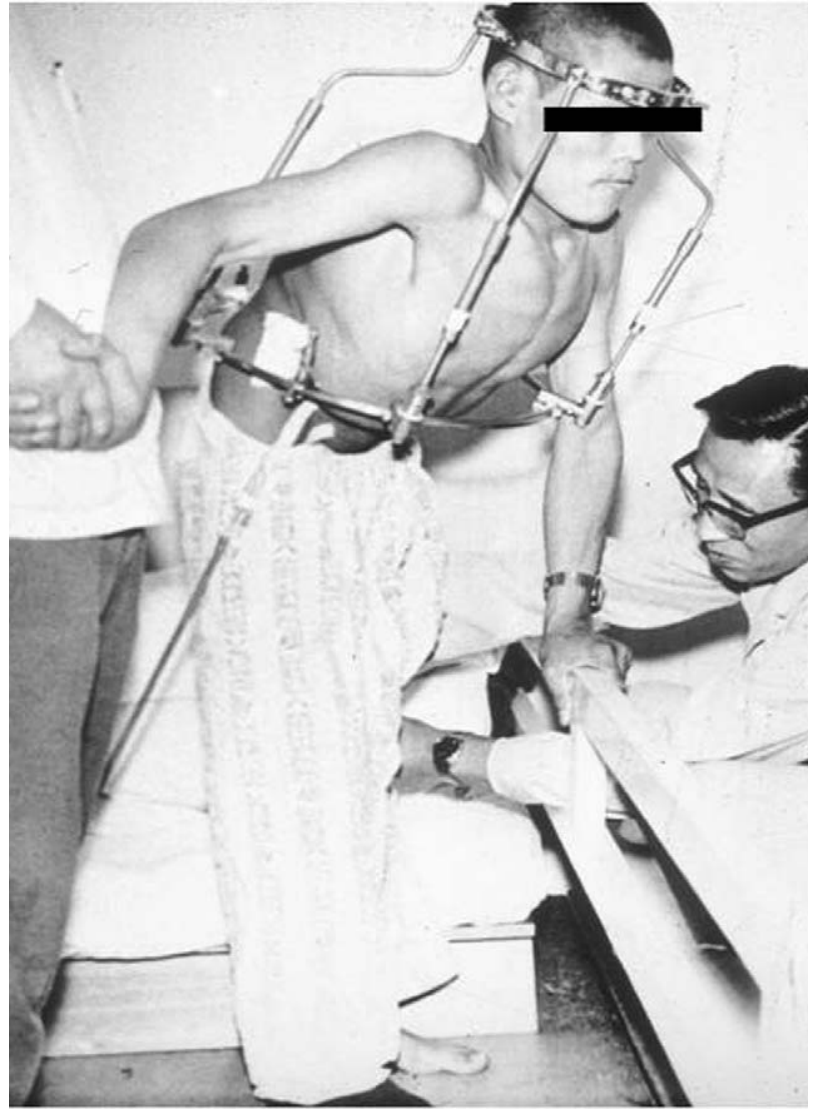

Fig. 2. The halo-pelvic apparatus was fit onto the patient.
T12-L4 kyphotic Cobb's angle of $100^{\circ}$ with severe destruction of the vertebral body from L1-L4. A lumbar myeolgram demonstrated a complete block of CSF flow at L4-5. The patient's height and weight on admission were, respectively, $142 \mathrm{~cm}$ and $50.0 \mathrm{~kg}$.

One week before spinal surgery, we fit a halo pelvic apparatus onto the patient so that he could adapt to it and develop confidence with his breathing (Fig. 2). The patient underwent anterior correctional osteotomy and release. After surgery, the apparatus was re-fit onto the patient, and distraction was begun. The bars were wound down, on average, $2 \mathrm{~mm}$ each day. Daily calculation of the force applied to the spine was made from measurements of the springs incorporated into the halo hoop device and recorded. We carefully monitored whether the neurological deficit got worsening.

During distraction for 2 months, he had no neurologic deterioration and no back pain. After distraction, posterior osteotomy and release were performed to achieve final correction because flexibility of the kyphosis was not sufficient. At the posterior surgery, autologous rib bone grafting was also performed simultaneously. After a second operation, distraction was maintained at the same rate for another three weeks. Total correction took eleven weeks.

After distraction for 11 weeks, the kyphotic deformity was corrected to a Cobb's angle of $62^{\circ}$ from T12 to L4. 


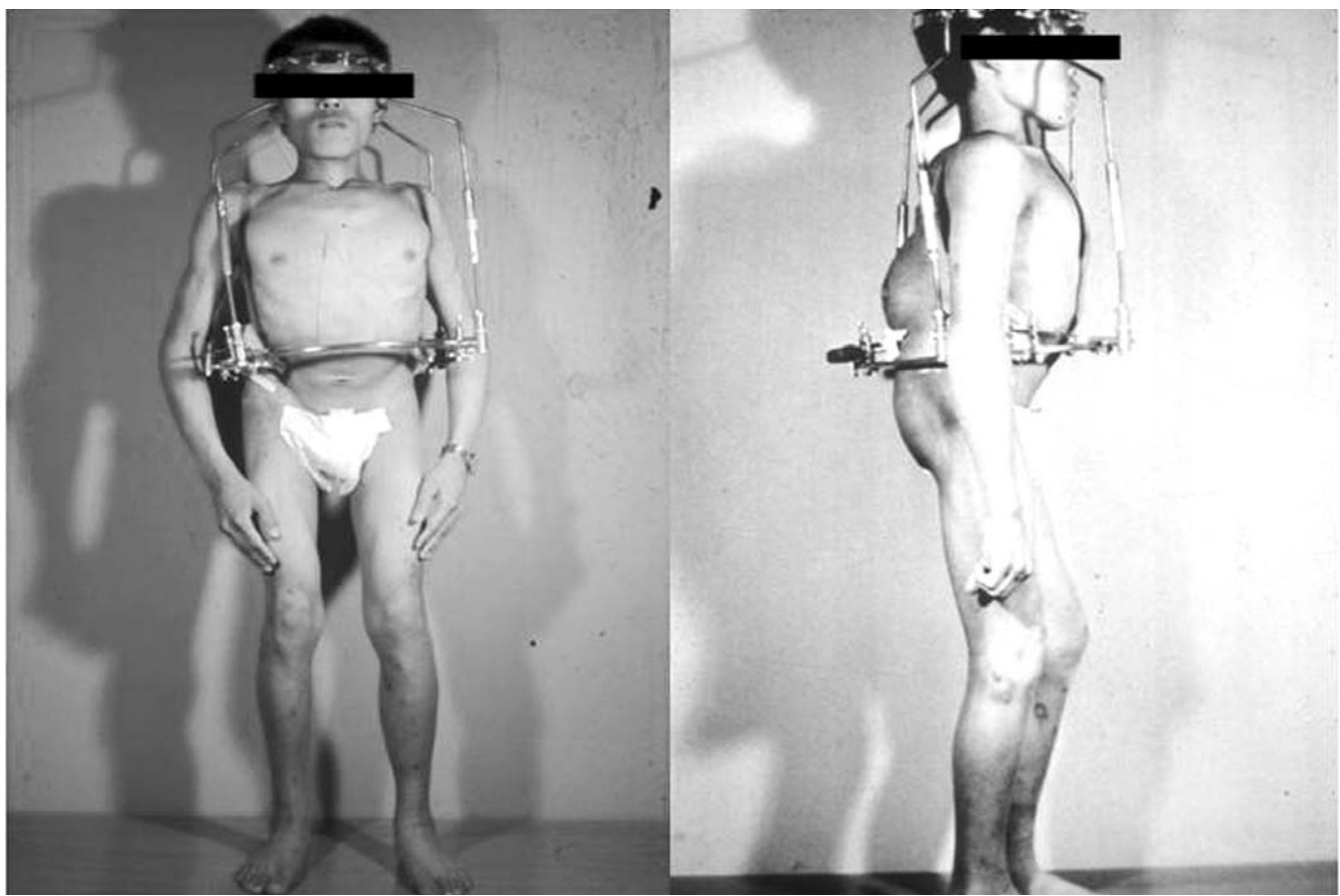

Fig. 3. The patient could stand without any assistance.

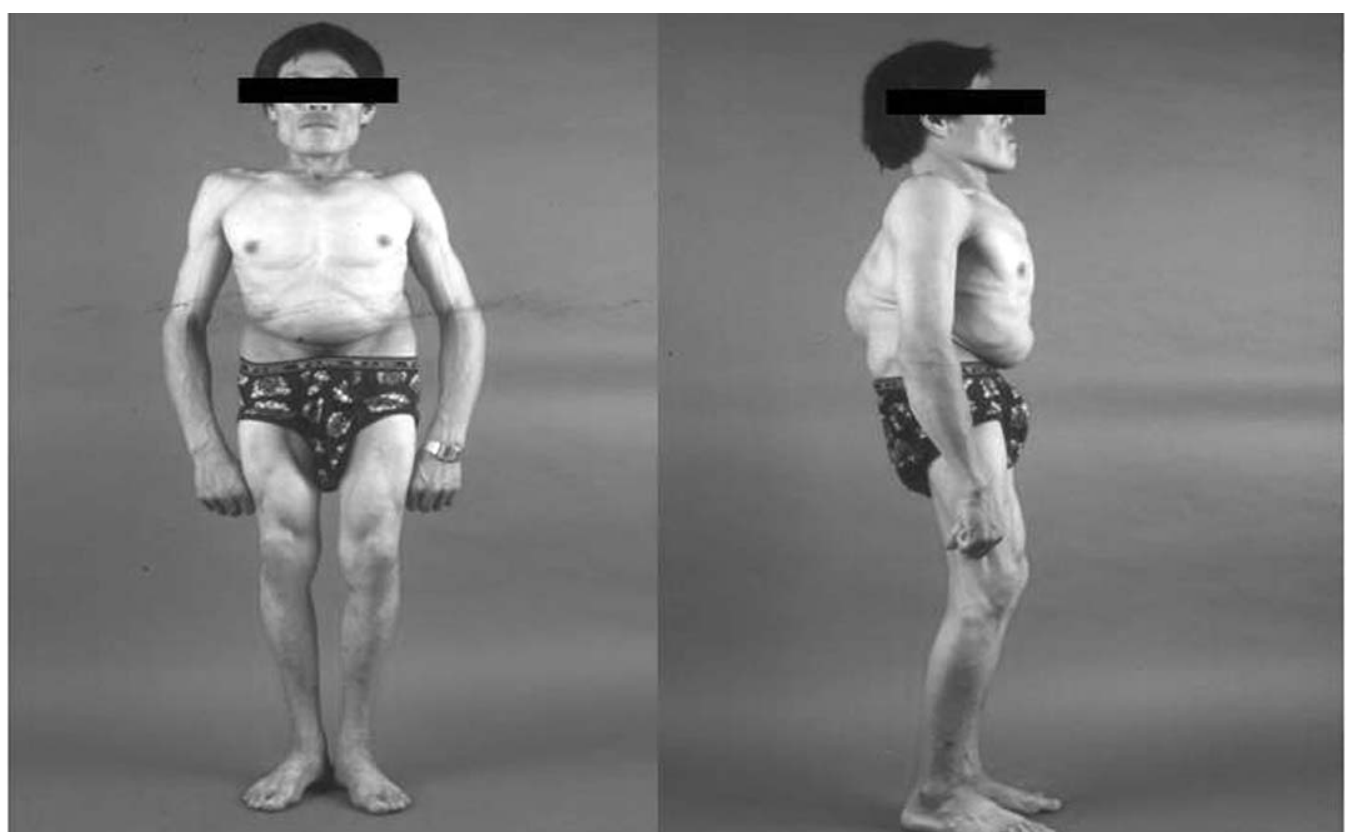

Fig. 4. Twenty years after the operation, the correction angle was maintained without neurologic symptoms.

After correction, the patient's height increased to $150 \mathrm{~cm}$ from $142 \mathrm{~cm}$. In order to maintain the correction, supplementary anterior fusion was done using an autologous iliac bone graft. The apparatus was removed when the grafts had consolidated.

During these procedures, there was no specific complication related to the halo pelvic distraction, and the patient's previous paralyzed lower extremities recovered gradually so that the patient could stand and walk without any assistance 6 months after the operation. He could look straight ahead without knee flexion after the 3rd operation (Fig. 3).

The patient had been followed for 20 years after correction of the tuberculous kyphosis using osteotomy and halopelvic traction. The patients had no neurological deteriora- 


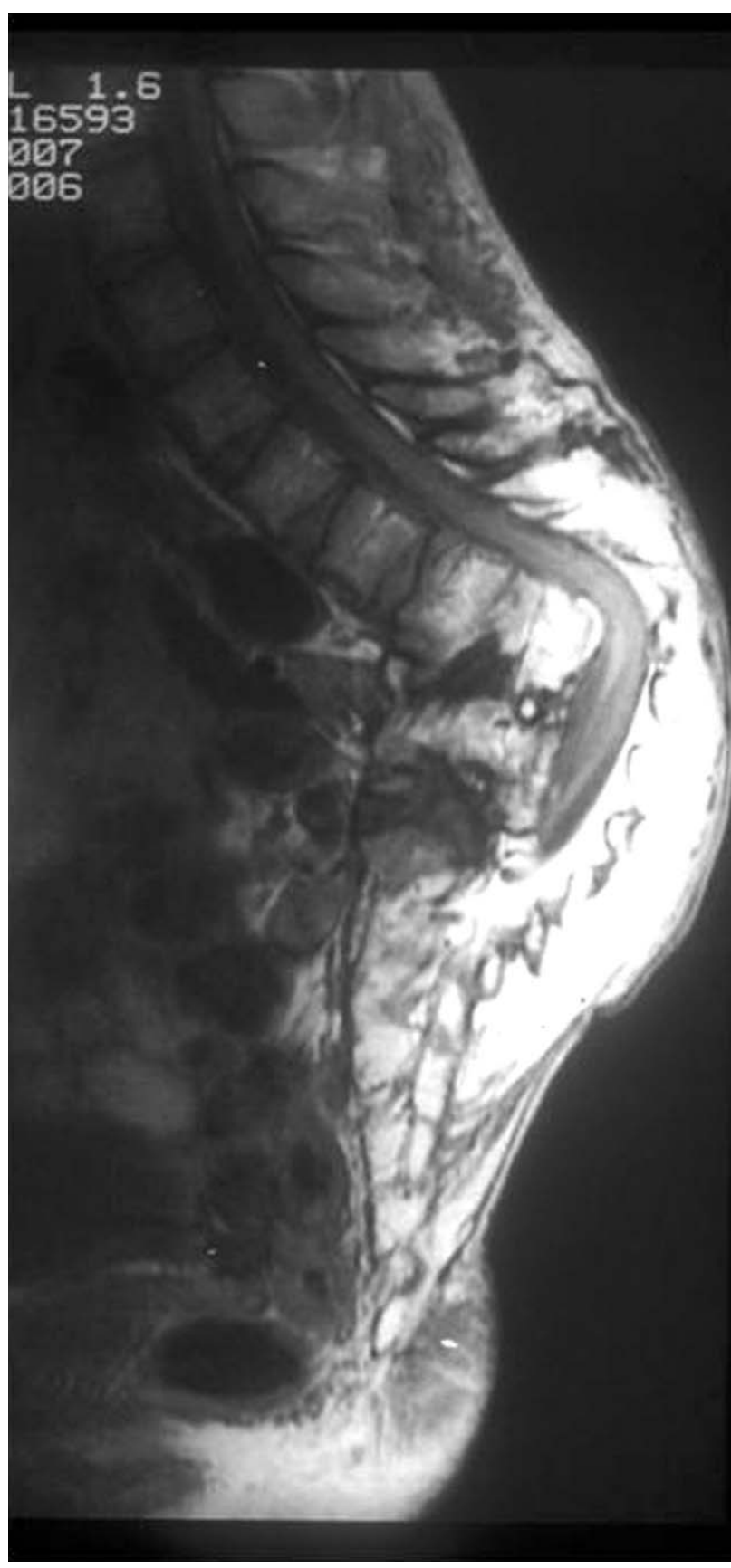

Fig. 5. Follow-up MRI twenty years after the operation: There was no spinal canal compression even though the kyphotic deformity remained.

tion, and could walk without use of a walking device. He had no back pain or leg pain and no limitation to his daily activity. He stated that he could work as a farmer using agricultural machines. Correction angle and good sagittal balance were well maintained (Fig. 4). At a follow up MRI (magnetic resonance image) taken twenty years after treatment, there was no compression of the dural sac (Fig. 5).

\section{Discussion}

Before the 1970s, a severe tuberculous kyphotic deformity was a very troublesome disease to be treated by spinal surgeons. However, since O'Brien et al. ${ }^{1}$ first demonstrated a halo-pelvic apparatus to correct spine deformities such as kyphosis or scoliosis, tuberculous kyphoses have been successfully corrected. This troublesome deformity can also be corrected surgically, and to the best of our knowledge, our case is the first in Korea in which tuberculous kyphosis was treated using spinal osteotomy and halo-pelvic traction.

In recent times, there have been several surgical methods used to treat tuberculous kyphosis, including single-staged posterior decompression and fusion, posterior instrumentation and anterior arthrodesis in one or two stages, and single-stage decompression and anterior interbody fusion with posterior instrumentation ${ }^{3-5}$. Further, Jain et al. ${ }^{6}$ reported an ideal procedure for correction of spinal tuberculosis kyphosis anterior corpectomy followed by posterior column shortening, instrumented stabilization, and reconstruction of the anterior gap by grafting in one stage.

In fact, halo-pelvic traction has a definite handicap, compared to more recently developed methods. It demands endurance from patients, who need to wear a big and burdensome apparatus for several months. For this reason, its recent use has not been frequent. Despite this shortcoming, however, the halo-pelvic apparatus has advantages over other recently introduced methods, in which angular correction is achieved rapidly and suddenly. In the latter methods, there could be serious neurologic deteriorations, especially in the compromised spinal cord, that is produced by continuous stretching of the spinal cord over the transverse ridge of the bone in the tuberculous kyphotic deformity ${ }^{6-9}$. Moreover, because a healed tuberculous kyphosis in an adult is very rigid and angled acutely, the spinal cord has poor tolerance to the traction.

On the contrary, the halo-pelvic apparatus produces high corrective forces applied over a long period of time, and it allows a slow and safe correction of a deformity. In the present case, the patient had a very rigid kyphotic deformity and also had progressive neurologic deterioration in both legs, that is, late-onset paraplegia, which is observed frequently in patients with long-standing healed kyphosis of $60^{\circ}$ or more ${ }^{10}$. In this case, the overall prognosis had been reported as poor because of anticipated poor neural recovery ${ }^{7,8,10}$. Therefore, we think that a halo pelvic traction was 
the safest and the efficient method for the correction of this patient's rigid kyphosis with progressive worsening of his neurologic deficit.

This report also demonstrates that adequate correction using a halo pelvic apparatus can last over twenty years without any neurological symptoms. Because this is the first case using halo-pelvic traction in Korea, it should set an example of how to correct severe spinal deformity surgically. In conclusion, halo-pelvic traction could be of great value in the treatment of severe and rigid kyphotic deformities, while avoiding many serious complications from a rapid, one-stage correction.

\section{REFERENCES}

1. O'Brien JP, Yau AC, Smith TK, Hodgson AR: Halo pelvic traction: a preliminary report on a method of external skeletal fixation for correcting deformities and maintaining fixation of the spine. J Bone Joint Surg Br 1971; 53: 217-229.

2. Yau AC, Hsu LC, O'Brien JP, Hodgson AR: Tuberculous kyphosis: correction with spinal osteotomy, halopelvic distraction, and anterior and posterior fusion. J Bone Joint Surg Am 1974; 56: 1419-1434.
3. Guven O, Kumano K, Yalcin S, Karahan M, Tsuji S: A single stage posterior approach and rigid fixation for preventing kyphosis in the treatment of spinal tuberculosis. Spine (Phila Pa 1976) 1994; 19: 1039-1043.

4. Moon MS, Woo YK, Lee KS, et al: Posterior instrumentation and anterior interbody fusion for tuberculous kyphosis of dorsal and lumbar spines. Spine (Phila Pa 1976) 1995; 20: 1910-1916.

5. Laheri VJ, Badhe NP, Dewnany GT: Single stage decompression, anterior interbody fusion and posterior instrumentation for tuberculous kyphosis of the dorso-lumbar spine. Spinal Cord 2001; 39: 429-436.

6. Jain AK, Maheshwari AV, Jena S: Kyphus correction in spinal tuberculosis. Clin Orthop Relat Res 2007; 460: 117123.

7. Hsu LC, Cheng CL, Leong JC: Pott's paraplegia of late onset: the cause of compression and results after anterior decompression. J Bone Joint Surg Br 1988; 70: 534-538.

8. Jain AK: Treatment of tuberculosis of the spine with neurologic complications. Clin Orthop Relat Res 2002; (398): 75-84.

9. Bilsel N, Aydingoz O, Hanci M, Erdogan F: Late onset Pott's paraplegia. Spinal Cord 2000; 38: 669-674.

10. Tuli SM: Severe kyphotic deformity in tuberculosis of the spine. Int Orthop 1995; 19: 327-331. 